\title{
BMJ Open Exploring provision of Innovative Community Education Placements (ICEPs) for junior doctors in training: a qualitative study
}

\author{
Ann Griffin, ${ }^{1}$ Melvyn M Jones, ${ }^{2,3}$ Nada Khan, ${ }^{2}$ Sophie Park, ${ }^{2}$ Joe Rosenthal, ${ }^{2}$ \\ Vasiliki Chrysikou ${ }^{2}$
}

To cite: Griffin A, Jones MM, Khan N, et al. Exploring provision of Innovative Community Education Placements (ICEPS) for junior doctors in training: a qualitative study. BMJ Open 2016;6:e009931. doi:10.1136/bmjopen-2015009931

\section{- Prepublication history} and additional material is available. To view please visit the journal (http://dx.doi.org/ 10.1136/bmjopen-2015009931).

Received 2 October 2015 Revised 16 December 2015 Accepted 15 January 2016

\section{${ }^{1}$ University College London Medical School, London, UK ${ }^{2}$ Research Department of Primary Care and Population Health, UCL, London, UK ${ }^{3}$ Warden Lodge Surgery, Herts, UK}

Correspondence to Dr Melvyn Jones; melvyn.jones@ucl.ac.uk

\section{ABSTRACT}

Objective: Medical education in community settings is an essential ingredient of doctors' training and a key factor in recruiting general practitioners (GP). Health Education England's report 'Broadening the Foundation' recommends foundation doctors complete 4-month community placements. While Foundation GP schemes exist; other community settings, are not yet used for postgraduate training. The objective of this study was to explore how community-based training of junior doctors might be expanded into possible 'innovative community education placements' (ICEPs), examining opportunities and barriers to these developments.

Design: A qualitative study where semistructured interviews were undertaken and themes were generated deductively from the research questions, and iteratively from transcripts.

Setting: UK community healthcare.

Participants: Stakeholders from UK Community healthcare providers and undergraduate GP and community educators.

Results: Nine participants were interviewed; those experienced in delivering community-based undergraduate education, and others working in community settings that had not previously trained doctors. Themes identified were practicalities such as 'finance and governance', 'communication and interaction', 'delivery of training' and 'perceptions of community'. ICEPs were willing to train Foundation doctors. However, concerns were raised that large numbers and inadequate resources could undermine the quality of educational opportunities, and even cause reputational damage. Organisation was seen as a challenge, which might be best met by placing some responsibility with trainees to manage their placements. ICEP providers agreed that defined service contribution by trainees was required to make placements sustainable, and enhance learning. ICEPS stated the need for positive articulation of the learning value of placements to learners and stakeholders.

Conclusions: This study highlighted the opportunities for foundation doctors to gain specialist and generalist knowledge in ICEPs from diverse clinical teams and patients. We recommend in conclusion ways of dealing with some of the perceived barriers to training.

\section{Strengths and limitations of this study}

- Novel findings from previously unheard informants in this field.

- Recruiting from a wide range of non-traditional learning organisations among UK community health providers.

- Possible responder bias based on sampling existing institutional contacts.

- Relatively small numbers of participants, although undergraduate community educators can give insights from a larger numbers of organisations.

\section{BACKGROUND}

In the UK Foundation doctors (junior doctors within 2 years of qualifying) largely are trained in hospitals. The recent report by UK National Health Service (NHS) Health Education England (HEE), 'Broadening the Foundation Programme', has highlighted the need for medical trainees to gain a wider experience of community healthcare ${ }^{1}$ and recommends that at least $80 \%$ of foundation programme (FP) doctors should undertake a 4-month community or integrated placement from August 2015 rising rapidly to $100 \%$ in August 2017.

The proposed expansion of communitybased placements aims to refocus attention and develop foundation doctors who are more knowledgeable about the range of settings for healthcare, understand how teams facilitate seamless patient care, work across interfaces and develop flexible approaches to clinical provision. ${ }^{1}$ There are calls for all doctors to develop more generalist skills, to cope with rising comorbidity among ageing populations. ${ }^{2}$ Persuading more entrants to general practice has also risen up the UK political agenda in 2015. ${ }^{3}$ However, general practice, the predominant sites for UK 
community-based education is at capacity. ${ }^{4}$ The HEE report's authors urge educators to think more widely about educational settings and suggested innovative community-based placements.

Healthcare education has historically tended to focus on knowledge, particularly on 'science' content. ${ }^{5}$ Most early postgraduate (PG) training of UK doctors still happens in hospital settings although FPs now offer a proportion of trainees a placement in general practice (18\% of $\mathrm{F} 1$ and $42 \%$ of $\mathrm{F} 2$ posts). ${ }^{1}$ However, more undergraduate (UG) medical education is now community based; a change to address students' educational needs (gaining a better understanding of disease, its prevalence and management), within the context of increased student numbers and shorter patient hospital stays. ${ }^{6}$ These changes potentially broaden the types of knowledge valued by faculty and learners.

Definitions of community-based placements vary and are contested. The 'Broadening' report describes them as:

Primarily based in a community setting. The learning outcomes will .. include the care of the total patient .. long-term conditions and the increasing role of community care. ${ }^{1}$

Community-facing programmes are those based within an acute setting which offer a mixture of community and community-facing care. Hays ${ }^{7}$ offers "A pancommunity approach includes all possible healthcare facilities as potential sites of teaching."

We defined 'Innovative Community Education Placements' (ICEP) providers as those working in settings where education for healthcare professionals for and specifically PG medical trainees is currently not a mainstream activity of these organisations.

We aimed to understand how training for junior doctors may be further extended in to the community with the objectives of understanding; what could be learnt by FP doctors, exploring how they might be supervised, while exploring the barriers and facilitating factors for taking these trainees.

\section{METHODS}

Interviews

PG community-based placements are being proposed as hosts for foundation doctors, yet there is little existing experience of community-based PG training (outside of general practice). We therefore looked to draw on the experience of UG general practitioner (GP) educatorswhere placements already exist. We therefore conducted semistructured interviews (see interview schedule online supplementary appendix 1) with two groups of informants: those currently providing community-based teaching identified by the research team and the commissioners as potential key informants; and those that could provide teaching in ICEPs. These participants were identified through a widely disseminated web-based survey of potential providers and a snowballing approach of the research team's contacts. Survey respondents were invited to be interviewed.

The interview schedule was developed and informed by experience of the steering group in recruiting ICEPs and underpinned by the relevant literature to explore what an ICEP provider might look like, by exploring UG experience and perceived barriers and positive factors for potential providers.

\section{Qualitative data analysis}

Semistructured interviewing allows respondents to shape the interview process, treats them as experts, and is designed to uncover their own versions of the world while permitting researchers to reach a greater depth than survey-based methods. ${ }^{8}$ These features were particularly important when attempting to draw on the expertise of key respondents on a specialised domain of knowledge, and also when attempting to explore novel areas. We used a thematic analysis approach to data analysis, which allowed for emerging themes, not on our original topic guide, and comparisons to be made between participant responses. ${ }^{9}$ Initial themes for coding were generated deductively from the research questions with further themes produced iteratively from within the transcripts, with two researchers generating themes independently (NK and VC). An inter-rater coding agreement of over $85 \%$ was achieved. NVivo 10 was used to manage and organise data. Three researchers (SP, NK and VC) held two data workshops to organise the coding framework. The results are illustrated with verbatim quotes.

\section{Ethics}

This study was reviewed as a service evaluation and received ethical approval from the UCL Joint Research Office.

\section{RESULTS}

We received 45 respondents to the snowball survey (from a targeted initial sample of 126 organisations which do not provide placements to junior doctors). All respondents indicating a willingness to be interviewed, were included in this study, which generated nine in-depth interviews from a range of stakeholders. Interviews were carried out face to face and over the phone, lasting between 30 and 90 min (see table 1 ).

The coding framework included four main categories (see figure 1 about here).

\section{Finance and governance}

Interviewees highlighted finance and governance as key issues when taking on trainees. These included financial support for trainers, logistical and administrative support, indemnity, promoting safety, governance, time management, quality assurance and service specific logistical constraints.

Financial issues were seen as an obstacle to most interviewees, but not all. 
Table 1 Description of interviewees

\begin{tabular}{|c|c|c|c|c|}
\hline & Organisation type & $\begin{array}{l}\text { Currently } \\
\text { (FP) } \\
\text { training }\end{array}$ & $\begin{array}{l}\text { Level of } \\
\text { trainees } \\
\text { (if any) }\end{array}$ & Placement experience \\
\hline Participant 1 & $\begin{array}{l}\text { UG Community based teaching lead } \\
\text { traditional metropolitan medical school } \\
\text { (1)/GP training (GPT) PG course } \\
\text { organiser for acute trust }\end{array}$ & No & $\begin{array}{l}\text { MS (all years)/ } \\
\text { GPT }\end{array}$ & MS/GPT \\
\hline Participant 2 & $\begin{array}{l}\text { MS (school 1) community placement } \\
\text { organiser }\end{array}$ & No & $\begin{array}{l}\text { MS (year } 1 \\
\text { and 2) }\end{array}$ & $\begin{array}{l}\text { GP, community services for example, } \\
\text { 3rd sector provider-Age UK, youth } \\
\text { projects, drugs/alcohol misuse } \\
\text { services }\end{array}$ \\
\hline Participant 3 & $\begin{array}{l}\text { Director of a FP school/deanery (linked } \\
\text { to traditional metropolitan medical } \\
\text { school 3) }\end{array}$ & Yes & FP doctors & $\begin{array}{l}\text { Private hospital and health providers, } \\
\text { Urgent Care Centres, FP, community } \\
\text { post in Acute trusts (community } \\
\text { paediatrics), PG GP placements, 3rd } \\
\text { sector providers for example, } \\
\text { MacMillan nurses }\end{array}$ \\
\hline Participant 4 & $\begin{array}{l}\text { Community placement lead Metropolitan } \\
\text { traditional medical school ( } 3 \text { ) } \\
\text { Public health/health promotion lead }\end{array}$ & No & MS (all years) & $\begin{array}{l}\text { Sickle-cell organisation, prisons, } \\
\text { homeless charitable providers, mental } \\
\text { health 3rd sector providers, local } \\
\text { government sport centres (exercise on } \\
\text { referral programmes), services (Royal } \\
\text { Navy), asylum health provider (3rd } \\
\text { sector), secure mental health provider, } \\
\text { sexual health (genitourinary medicine, } \\
\text { contraception), local authority and } \\
\text { public health }\end{array}$ \\
\hline Participant 5 & $\begin{array}{l}\text { Interprofessional education lead- } \\
\text { medical (traditional medical school } \\
\text { (4))/and University providing other } \\
\text { healthcare students education for } \\
\text { example, nursing, paramedics }\end{array}$ & No & $\begin{array}{l}\text { MS/nurses/ } \\
\text { paramedics }\end{array}$ & $\begin{array}{l}\text { Prehospital care ambulance services } \\
\text { (inc helicopter services)/probation } \\
\text { services/schools }\end{array}$ \\
\hline Participant 6 & Prison doctor & No & None & Occasional GPT/MS \\
\hline Participant 7 & $\begin{array}{l}\text { PG Training programme director } \\
\text { paediatric role with } \\
\text { Specialist Community service }\end{array}$ & No & PST doctors & $\begin{array}{l}\text { Foundation docs GP and PST with } \\
\text { specialist services for example, } \\
\text { community sickle-cell services }\end{array}$ \\
\hline Participant 8 & $\begin{array}{l}\text { GP out of hours provider (non NHS } \\
\text { social enterprise) } \\
\text { Non metropolitan location }\end{array}$ & No & $\begin{array}{l}\text { GPT, some } \\
\text { non-medical } \\
\text { training for } \\
\text { example, } \\
\text { paramedics/ } \\
\text { nurses }\end{array}$ & $\begin{array}{l}\text { Potential for non GPT for example, } \\
\text { specialists/FP docs in GP out of hour } \\
\text { settings, patients homes, UCC, walk in } \\
\text { clinics }\end{array}$ \\
\hline Participant 9 & Pregnancy advisory service (3rd sector) & No & $\begin{array}{l}\text { Gynaecology } \\
\text { trainees }\end{array}$ & $\begin{array}{l}\text { Potential for FP/MS generic sexual } \\
\text { health skills, and specific } \\
\text { gynaecology/surgical skills }\end{array}$ \\
\hline
\end{tabular}

FP, foundation programme; GP, general practitioner; GPT, GP training; MS, medical students; NHS, National Health Service; PG, postgraduate; PST, paediatrics speciality training; UCC, urgent care centre; UG, undergraduate.

Anybody who's considering doing any kind of community placement... resource is really important...money and the staff...if you cut corners ... it's untenable to be honest. (Participant 2)

Extra funding was seen by some as essential to pay for trainers and administrative support while conversely, some organisations saw training as 'part of their role' and consequently not requiring extra financial support.

The interviewees felt that logistical/administrative issues were a considerable challenge and that having the appropriate structure and organisation was key to successful training programmes. Possible logistical solutions included leaving the responsibility for organising the day to day attendance at placements with trainees (as with some UG placements), increasing their responsibility as learners and reducing administration. Examples of facilitative behaviours included trainees using tools such as websites to sign up for community sessions.

We had previously identified trainees' indemnity issues as a potential obstacle to ICEPs, however, most of the 
Figure 1 Coding framework for

facilitative aspects and barriers

for training in community settings.

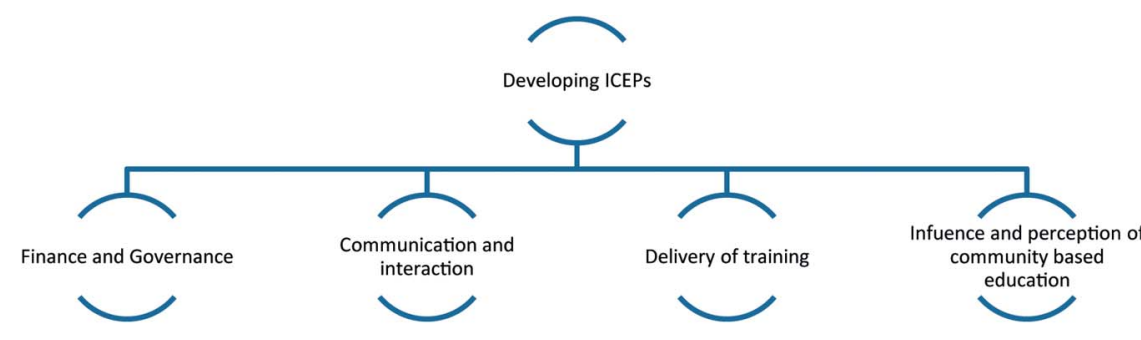

Trainees in this environment also developed professional competencies in learning to manage complexity, managing clinical conditions in combination with factors such as drug use.

(In) the prison...there is a huge potential for education and for experience for junior doctors working with a particularly disadvantaged group of people who have very severe health needs. (Participant 6)

Facilitating trainee-patient interaction was perceived by some of the interviewees as a key purpose of learning in the community, gaining new perspectives on how to tailor care to complex patients; one described a 'co-production' community project:

[The trainee] took this young kid off to McDonald's and...got them thinking creatively...asking them about their experience of sickle cell and what would make that better. Actually what came out ... yeah the pain was terrible... far more of a problem to them was stigma .... The scales fall off their eyes, so they realise the gap between what they're (actually) providing ... \& they think they're providing. (Participant 7)

This reflected a strong orientation among interviewees that instilling patient-centred values and facilitating the interaction between trainees and patients are valuable aspects of community placements. Respondents also highlighted that developing 'hard-nosed' clinical acumen from learning to manage challenging medical conditions was still at the heart of many potential community placements.

[Doctors] don't often get the opportunity to have training within the NHS, because a lot of services have been outsourced to organisations like us. (Participant 9)

Trainee-patient interactions also had a beneficial impact for patients as trainees often had more time with clients so the encounter had a more therapeutic value:

Patients like that chance to talk to a student about their care and their problems...the student can spend an hour with them... And it makes them feel better and gets more information.' (Participant 1)

Difficulties sometimes arose when trainees worked with marginalised groups, emphasising the need for appropriate preplacement training and trainee support: 
Work(ing) with very socially stigmatised or disadvantaged groups...there is potential if medical students or trainee doctors going in there with poor attitudes or skills...for it to be not a positive experience. ..ideally they need to be supported... before they go in.' (Participant 2)

\section{Delivery of learning and teaching \\ Supervision}

Supervision was viewed as a critical component to making successful placements. Having a clinical supervisor in-situ, created a safe learning experience, and recognised the boundaries of trainee expertise.

Close and senior enough supervision is important. Because this is uncharted territory .... quite often ... difficult for a foundation trainee to...able to contribute...in these settings. (Participant 7)

Training for community trainers elicited a range of views, an UG teaching faculty interviewee described,

Sometimes [community staff] don't feel trained or able to teach medical students... a lot of support is often needed. (Participant 4)

When we discussed the role of the clinical supervisors and trainers, and multidisciplinary staff taking on these roles; one interviewee described the legitimacy of multidisciplinary trainers:

Interviewer: Were the paramedics able to sign the students off for clinical skills?

Respondent: No we didn't get involved in that because we thought that would be 1) unfair, and 2) probably legally problematic.' (Participant 5)

There was variability of views about the clinical role of the community trainers and supervisors, with many informants feeling that although trainers might not always be able to sign off competencies if they were not a doctor, they could be legitimate supervisors of trainees-especially when they were the usual clinician in that context (eg, Ambulance paramedic). While some valued the contextual knowledge of the professional, others favoured the tribal identity of the teacher:

[The supervisor should be] a qualified health professional who cares really... interested in their learning ... if they (students) have got something to learn from them. (Participant 1)

contrasting with the view that supervisors should be exclusively doctors.

No. It's a real definite no.. the nominated clinical supervisor I think should always be a doctor. ...I think it carries more risk if you do it (supervision) in the community setting. (Participant 3 ) and so if a doctor is not present in the ICEP setting on a daily basis, as is often the case in many community health providers, this will produce operational tensions for potential ICEPs and trainees.

Once community placements were set in place, it was viewed as important to maintain a support structure for clinical supervisors and trainers.

\section{Models for organising ICEP placements}

Participants discussed a range of models for teaching in community placements including project-based learning, blended learning ${ }^{10}$ and 'hub and spoke' models.

Actually 4 months in an urgent care centre (UCC) is not a particularly good ...experience. Split it-make it integrated ... increasing the value of the programme... in an UCC...you see how you prevent people coming to hospital...in an acute medical unit you're seeing the people coming to hospital-I think is a good learning experience. (Participant 3)

Setting up new ICEPs requires time and commitment. Tensions were identified within existing organisational infrastructure between service delivery and teaching:

It would be impossible to properly mentor a junior doctor... it would be a great training experience for doctors, but I cannot imagine how we could get sufficient time ...so that they weren't feeling completely out of their depth. (Participant 6)

Experienced providers mentioned the importance of piloting and evaluating:

What I have learnt is that you have to test these things out. ...it's been so helpful and we've adapted things as we've gone along because of our experiences. (Participant 7)

\section{Peer learning opportunities}

Peer learning was viewed as a positive way to promote learning.

The students are always in pairs... I think a really good model because...they've got each other. But also it means they can experience the same situation and have different responses to it and come away and talk about that. (Participant 2)

Emphasising the importance of debriefing sessions, allowed trainees to maximise learning through reflection on each different experience.

\section{Learning agendas}

It was felt important to consider the learning objectives at an early stage in order to help trainees make links between their learning and their community experiences,

It isn't just about filling their diary or the timetable.... sometimes students will say... when they're graduating 
'I can see the link now, but you should have told us that at the time'. (Participant 4)

\section{Influence and perception of community-based education Attitudes to community placements}

Participants identified a need to change trainees' views about community placements with some perceiving community learning opportunities as supplementary rather than integral to their education. Others noted that community placements were essential to provide learning experiences that were not available in the mainstream NHS training

They get to observe...clinical care that they wouldn't otherwise see if they're ...within the hospital. ...they also learn something about the complexity of navigating the system, the importance of joined up working, the importance of good communication... (Participant 7)

Seeing community placements as 'non-essential' was, however, seen as a barrier, especially if other healthcare professionals also devalued community programmes:

Understanding by all concerned that community placements are an integral part of the learning, not an add-on optional extra...students ...will understand it better if teachers ... reinforce it...if the consultant surgeon says 'oh why are you going to GP tomorrow?' ... that devalues ... our programme. (Participant 1)

One of the interviewees expressed concerns about the value of the available knowledge in the community setting:

We [don't want to] put people into inappropriate training posts that they feel they're not learning. ...and we discover there's a lot of unhappy foundation doctors. And my worry ....and they start saying to us 'Well what am I doing here?' ... you pay me for 4 months to go and put up posters for a charity organisation and sit and dole out contraceptives... Is that really going to advance me into my speciality training?' (Participant 3 )

Placement organisers recognised the issues of fragmentation and a lack of clarity of learning aims. Supervision from someone with detailed knowledge of the learning objectives was noted to mitigate against the threat to coherency.

Essentially I think what we've designed is something where we're linking up a trainee with somebody ... who has quite a lot of experience of integrated care ... so I can call that a 'faculty' ... and then a local champion, ... who has an interest in supporting this. (Participant 7)

\section{Community advocates}

Successful placements required community-based advocates who were motivated about teaching and exposing trainees to marginalised client populations:
[The trainers are] "often...working with quite socially excluded or disadvantaged individuals...I think therefore they are really keen to contribute to medical education... just because they can see that it's part of a whole". (Participant 2)

\section{Definition of generalist or specialist knowledge}

There were a range of views on community training and whether available knowledge was generalist or specialist. One participant highlighted the specialist nature of community-based knowledge in family planning clinics and termination of pregnancies:

so if we want to have a workforce in the future we need to engage with providing training. ..to try to bring those trainees into our clinics and teaching them how to do procedures. (Participant 9)

More often, community placements were anticipated to provide generalist knowledge. Participants felt that community placements championed and provided learning opportunities for generalist skills.

You're training less people with a general approach while.. an ageing society where often patients do have problems in more than one speciality...I think a return to generalism is welcome...the lines between health care and social care are getting ever more difficult to draw. .. and I think students learn really well from that kind of experience... (Participant 1)

\section{Benefits of learning in the community}

Interviewees described the additional learning opportunity in the community such as working with uncertainty and limited resources:

It's about learning how to work in an area that has restricted resources .. information.. time.. knowledge, .. certainty. I think they learn ... to improvise, to be innovative in how they approach their work. Working very independently ... you can learn confidence and skills. (Participant 8)

\section{DISCUSSION}

\section{Summary of main findings}

The study explored the barriers and facilitating factors for taking on trainees in innovative settings. The main themes included finance and governance, communication and interactions, the delivery of teaching and the influence and perception of community.

Many participants highlighted the value of learning opportunities in the community that reflected the aims of the 'Broadening' report, including gaining generalist skills, seeing health issues in context and learning about patient-centred care. ${ }^{1}$ Despite the anticipated value of community placements, these interviews highlighted the institutional stigma inherent within medical education, and perceptions of community settings being less valued than acute hospital settings by medical trainees and 
some faculty. These issues need to be explored, addressed and communicated to trainees and faculty to try to change these perceptions.

Community experts indicated that the capacity to offer learning placements was dependent on the funding available, without which there may be an impact on an organisation's ability to spend time developing and maintaining high-quality placements; adequate funding will address many of the concerns about servicetraining tensions.

The sort of knowledge a trainee is expected to learn in the setting will have an impact on the success of ICEPs but this is dependent on the services provided within that setting. The assumption that all community placements provide generalist knowledge might, however, be problematic in specialist services such as drug and alcohol clinics. While generalism might include features such as multimorbidity, it could be regarded as a particular approach to patients such as patient centredness; the latter perhaps being a more generic feature of ICEPs. Additionally organisational legitimacy may be an issue if community placements and supervisors are not empowered to assess and rate trainees, such as paramedics signing off a trainee's basic life support skills. This would have an impact on training capacity (if all work based assessments had to be done elsewhere) and credibility with trainees, if supervisors are of differing status.

\section{Strengths and limitations}

This is to our knowledge the first study of key opinion makers in this field of potential community hosts for medical education. The results highlight the very real obstacles to delivery of the 'Broadening the foundation' report. There are, however, limitations to our study; we conducted interviews with nine respondents so caution is needed in interpreting the results. The aim of this study was not, however, to provide data saturation, ${ }^{11}$ but to present a broad range of views ${ }^{12}$ derived from key informants both within community placement organisations as well as organisations which were not involved in this provision. Each informant should be regarded as representing a range of views from their organisation or for UG educators, as a proxy for a wide range of ICEPs, and not just as an individual.

Our findings are subject to response bias, and are likely to over-represent the level of interest in hosting clinical trainees as the sample is a non-random sample of providers who may be more likely to respond positively than others, through their connections or associations with the research team.

\section{Comparison with the existing literature}

Many of the themes from this study have some echoes in the literature including the Siggins-Miller literature review. ${ }^{13}$ From the learner's perspective community placements can have substantial benefits such as fostering well-rounded clinical competence and increasing student responsibility for patient care $^{14}$ although students may struggle to understand why they are not being taught or developing their skills in the acute hospital setting. From the patient and societal perspective, however, students may develop a deeper compassion and connection with patients. ${ }^{15}$ From a health service perspective, students training in the community show a higher preparedness to work in teams. ${ }^{15}$ These findings are echoed in our interviewees' responses about the value of community teaching and benefits to patients.

From the providers' perspective our findings echo concerns about the financial sustainability of these programmes, ${ }^{14}$ particularly where there is a tension between teaching and service delivery. ${ }^{16}$ Teaching is by necessity often opportunistic in community settings and structuring teaching is challenging, leading to concerns that the teacher's role is not always clearly defined. ${ }^{14}$ Organising such learning activity is also administratively complex due to the distance between the centralised host educational institution and the community providers. Additionally, the smaller scale of community providers means that multiple placements often need to be organised to accommodate increasingly large cohorts of trainees.

\section{Recommendations}

Several recommendations emerge from our research.

- Piloting new programmes is essential to identify potential problems.

- Organisations should involve trainees in supporting service delivery (where appropriate).

- Self-organisation of placements may reduce administrative burden.

- Community-based teaching champions are needed.

- Trainee discussions with experienced supervisors about the 'real world' value of community acquired skills should occur.

- Faculty development is required to maximise the supervisors' awareness of their trainees' needs and help them to develop appropriate teaching processes. Associate trainer schemes have been successful in other parts of the UK and may provide a helpful model to enable more healthcare professionals take part in supervision. ${ }^{17}$

\section{Implications for future research}

- How does learning takes place in non-traditional settings and ICEPs.

- How does training benefit learners, supervisors and the community. ${ }^{14}$

- What is the ideal length / mode of community placements.

Contributors AG was the $\mathrm{Pl} / \mathrm{grant}$ holder-oversaw delivery of the project involved in project design, analysis and write up. MJ was co applicant, involved in project design and write up of the project, lead for article submission. SP was the coapplicant, involved in project design, lead on qualitative analysis and project write up. JR was the coapplicant, involved in 
project design and contributed to generating sampling frame and involved in write up. NK undertook qualitative interviews and analysis and was involved in the write up. VC undertook qualitative interviews and analysis and was involved in the write up.

Funding This project was funded by Health Education North Central and East London (HENCEL).

Competing interests None declared.

Ethics approval UCL Joint Research Office.

Provenance and peer review Not commissioned; externally peer reviewed.

Data sharing statement No additional data are available.

Open Access This is an Open Access article distributed in accordance with the Creative Commons Attribution Non Commercial (CC BY-NC 4.0) license, which permits others to distribute, remix, adapt, build upon this work noncommercially, and license their derivative works on different terms, provided the original work is properly cited and the use is non-commercial. See: http:// creativecommons.org/licenses/by-nc/4.0/

\section{REFERENCES}

1. Broadening the Foundation Programme. ecommendations and implementation guidance, February 2014. Health Education England. https://hee.nhs.uk/our-work/hospitals-primary-communitycare/learning-be-safer/better-training-better-care-btbc/broadeningfoundation-programme

2. Royal College of General Practitioners. Call for Generalism. 2013. http://www.rcgp.org.uk/policy/rcgp-policy-areas/ /media/Files/Policy/ A-Z-policy/Medical-Generalism-Impact-Report-March-2013.ashx

3. NHS England. Boost the GP workforce. 2015. http://www.england. nhs.uk/2015/01/26/boost-gp-workforce/
4. GMC. The state of medical education and practice in the UK. GMC, 2012. http://www.gmc-uk.org/Summary The state of medical education_and_practice_in_the_UK_2012_English_0912.pdf_ 49860320.pdf

5. Whitehead C. Scientist or science-stuffed? Discourses of science in North American medical education. Med Educ 2013;47: 26-32.

6. Bryant P, Hartley S, Coppola W, et al. Clinical exposure during internal medicine attachments in general practice. Med Educ 2003;37:790-3.

7. Hays R. Community-oriented medical education. Teach Teach Educ 2007;23:286-93.

8. Byrne B. Qualitative interviewing. In: Seale C, ed. Researching society and culture. London: Sage, 2004:207-22.

9. Braun V, Clarke V. Using thematic analysis in psychology. Qual Res Psychol 2006;3:77-101

10. Christensen Institute. Blended learning. 2015. http://www. christenseninstitute.org/blended-learning-definitions-and-models

11. Seale C. The quality of qualitative research. London: Sage Publications, 1999.

12. Smith JA. Semi-structured interviewing and qualitative analysis. In: Smith JA, Harre R, Van Lagenhove L, eds. Rethinking methods in psychology. London: Sage, 1995:9-26.

13. Siggins Miller Consultants. Promoting quality in clinical placements: literature review and national stakeholder consultation. Health Workforce Australia, 2012.

14. Crampton PES, McLachlan JC, Illing JC. A systematic literature review of undergraduate clinical placements in underserved areas. Med Educ 2013;47:969-78.

15. Thistlethwaite JE, Bartle E, Chong AAL, et al. A review of longitudinal community and hospital placements in medical education: BEME Guide No. 26. Med Teach 2013;35:e1340-64.

16. Reynolds PP. Commentary: the teaching community health center: an idea whose time has come. Acad Med 2012;87:1648-50.

17. NHS Health Education England East of England. Associate Trainer scheme. 2015. https://heeoe.hee.nhs.uk/cpd primary care 